Article

\title{
A Review of Corporate Purpose: An Approach to Actioning the Sustainable Development Goals (SDGs)
}

\author{
Dayana Jimenez ${ }^{1}$, Isabel B. Franco ${ }^{2, *(\mathbb{D})}$ and Tahlia Smith ${ }^{3}$ \\ 1 Faculty of Business, Economics \& Law, St Lucia Campus, The University of Queensland, \\ Brisbane, QLD 4072, Australia; n.jimenezgarcia@uq.net.au \\ 2 Australian Institute for Business and Economics (AIBE), St Lucia Campus, The University of Queensland, \\ Brisbane, QLD 4072, Australia \\ 3 Australia-Latin America Business Council (ALABC), St Lucia Campus, The University of Queensland, \\ Brisbane, QLD 4072, Australia; tahliasmith121@gmail.com \\ * Correspondence: connect@drisabelfranco.com
}

Citation: Jimenez, D.; Franco, I.B.; Smith, T. A Review of Corporate Purpose: An Approach to Actioning the Sustainable Development Goals (SDGs). Sustainability 2021, 13, 3899 https://doi.org/10.3390/su13073899

Academic Editor: Roberta Costa

Received: 3 February 2021

Accepted: 22 March 2021

Published: 1 April 2021

Publisher's Note: MDPI stays neutral with regard to jurisdictional claims in published maps and institutional affiliations.

Copyright: () 2021 by the authors. Licensee MDPI, Basel, Switzerland. This article is an open access article distributed under the terms and conditions of the Creative Commons Attribution (CC BY) license (https:// creativecommons.org/licenses/by/ $4.0 /)$

\begin{abstract}
This journal article explores Corporate Purpose as an approach to action the Sustainable Development Goals (SDGs). It achieves this objective by presenting a review of existing literature on Corporate Purpose and SDGs from the disciplines of business ethics, management studies, economics and psychology. The review showcases contributions exploring whether and how Corporate Purposeled strategy facilitates the operationalization of the SDGs and proposes an emerging research agenda. This article employed an inductive approach methodology through grounded theory to develop a critical analysis of scientific evidence-based work for theory construction on Corporate Purpose. One of the major findings of this review is that to achieve the SDGs companies need to shift found from the "business as usual" approach, which perceives sustainability as an externality, to incorporating sustainability factors in the company's underlying purpose. The article also (1) identifies trends in research outputs and reveals five major antecedents of the phenomenon (drivers to purpose), (2) identifies key gaps within the existing literature, (3) distinguishes three current approaches to Corporate Purpose and (4) elaborates on current theories of Corporate Purpose and SDGs linkages to identify opportunities and aid future research. In summary, this article unpacks Corporate Purpose mechanisms to action the SDGs and stimulates academic discussion of business transformational approaches to long-standing sustainability challenges.
\end{abstract}

Keywords: corporate purpose; SDGs; sustainability; strategic management; purposeful business

\section{Introduction}

Amid a global crisis and economic slowdown, there is an urgent call for corporations to implement sustainable business strategies to ensure they can continue to create value for stakeholders and society as a whole even during times of disruption and uncertainty. By aligning corporate practices with the SDGs, companies can realize opportunities that generate financial returns as well as create long-lasting social and environmental impacts. Despite corporate commitments to meet social and environmental goals, the general limited understanding of businesses' purpose towards the realization of SDGs hinders the effectiveness of corporate and international agendas. Therefore, it is necessary to rethink existing business practices through a sustainability lens so that corporate concerns are more comprehensively addressed and SDGs operationalization has a greater global impact.

The fact that business strategies traditionally focus on maximizing profit instead of value creation inhibits local and national economies from being able to shift towards a more sustainable economic model [1-4]. Corporate Purpose is an alternative business approach which addresses this contradiction between profit maximization and sustainable value creation by focusing on creating purposeful profits and finding equal synergy between people, planet, and profits [5-7]. Therefore, this journal article aims to provide readers with 
an overview of concepts, issues and areas of further research on Corporate Purpose as a corporate approach to operationalizing the SDGs. The article is grounded in the United Nations SDGs. The SDGs are a global vision for inclusive, sustainable development which seeks a balance between meaningful economic growth, environmental wellbeing, and social justice [8]. Therefore, this article aims to explore the intersection between Corporate Purpose and SDGs as well as identify areas for further development and research. The implementation of this agenda will require business model innovations for sustainable development particularly in the corporate world. [9].

This article explores Corporate Purpose as an emerging model to action the SDGs. Corporate Purpose is a company's fundamental reason for being that goes beyond profits. It describes why a company exists and the impact it wants to make. Corporate Purpose conciliates profit with the needs of the planet and people, allowing businesses to be the most powerful vehicle to create social change. It defines why a company exists and the impact it can make. Corporate Purpose is not the company's vision and mission [10]. Instead, it represents an organizational transformation that helps to transcend the flaws of capitalism, supports corporations in transitioning to sustainable economies, and the operationalization of the SDGs in the private sector. The notion of Corporate Purpose involves the mechanisms by which corporations can contribute to society, and more specifically to the SDGs. Other definitions on Corporate Purpose can be consulted in Appendix A.

Corporate Purpose embeds the economic, social, and environmental value creation in the core business of an organization, creating meaningful impact for all stakeholders. Corporate purpose implementation consists of a design stage and an implementation stage. The design stage defines a Corporate Purpose statement, along with vision, values, goals, strategies, and Key Performance Indicators (KPIs); whereas the implementation stage focuses on purpose-led operation plan, purpose-led leadership mindset, and innovation culture.

According to leading literature, "purpose" goes beyond philanthropic initiatives [5,11-14]. It is an approach to measure business that matters to customers, employees and financial performance in the long term [1,15-17]. Similarly, studies show that purpose has become one of the fastest-growing strategic trends in businesses and businesses with a clear Corporate Purpose outperform in the market $[5,18]$. Corporate Purpose creates value by removing incentives for unsustainable business practices [19]. However, while a Corporate Purpose led strategy is becoming increasingly popular, there is currently limited academic literature about this topic $[3-5,17,20,21]$. The available Corporate Purpose literature is highly fragmented and lacks a holistic purpose measurement, while also excluding essential proxies [20,22]; therefore, the novelty and scarcity of relevant academic studies on this topic depict the need for further scholarly understanding of Corporate Purpose and Purpose-led business in general.

Alongside government, corporations play an essential role in the achievement of the SDGs in a purposeful manner. There has been a call for the private sector to apply innovation and creativity to address global sustainability challenges in a way that also provides benefits for businesses in the long term [23]. With only ten years to go to achieve the United Nations 2030 Agenda, private sector leaders are taking action [24]. The review shows that compliance with a corporate model grounded on the SDGs results in benefits for companies and their stakeholders, such as brand differentiation, customer and employee engagement, innovation, cost reduction, risk reduction, positive risk culture, value creation, and competitive advantage [25]. Business leaders around the world have started prioritizing Corporate Purpose as they begin to understand that successful and sustainable business practices require healthy societies.

For-profit organizations can build business models that allow the shift to a sustainable global economy [26,27] and in doing so overcome one of the biggest challenges to reaching the 2030 Agenda-operationalizing the SDGs [8]. Therefore, as SDGs "are the blueprint for achieving a better and more sustainable future for all" [28], it is highly relevant to explore 
how Corporate Purpose implementation can align and potentially contribute to this global vision by transforming thinking and practice about the role of corporations in society.

This article is divided into the following sections: research design, including applied methods and critical analysis; critical review of Corporate Purpose literature; critical review of the SDGs and their connection with Corporate Purpose; conclusion and opportunities for further research.

\section{Research Design}

\subsection{Methods}

In this article, we explore the following question: How is Corporate Purpose positioned as a model to incorporate sustainability and to what extent can it be applied as a model to action the SDGs? We developed our findings through inductive reasoning, by drawing on a literature review. According to Webster and Watson [29] the literature review as a research method produces solid ground for advancing science and promoting theory development. We applied a review followed by the protocol described by Tranfield et al., (2003) [30]. This protocol is widely accepted in business and management areas as an evidence-based approach to a review [31]. It suggests that there are three stages and nine phases in the successful development of a literature review [30]. Stage 1 -planning and justifying the review, drawing the proposal and the review protocol; Stage 2-executing the review, which involves the selection of studies, quality assessment, data extraction and data synthesis; Stage 3-reporting and disseminating the review, which involves writing the review and recommendations.

This research has been reviewed using an inductive approach through grounded theory [32]. The reason for the selection of this technique was to develop a critical analysis of ground scientific evidence-based work for theory construction. This method is particularly useful in studying the exploratory nature of this research which addresses Corporate Purpose as an emerging model to action the SDGs.

The study adopted a cross-sectional analysis approach to understand the development of the Corporate Purpose concept over the last 15 years. This literature is to be allocated with sustainability and management studies into the historical view of Corporate Purpose. Examining the Corporate Purpose concept and connected themes through an analysis of key ideas of current streams of thoughts enabled us to identify possible logical and conceptual similarities between authors on Corporate Purpose.

\subsection{Descriptive Analysis}

This review seeks further advancement in the field rather than replicability of the current estate of the notion of Corporate Purpose. The review involved the analysis of secondary sources on perspectives on Corporate Purpose. Both scholarship and policy analyses were conducted. Overall one hundred fifty (150) manuscripts were consulted, comprising of journal articles, book chapters, policy documents and advisory industry reports. Out of the total of consulted manuscripts, around sixty (60) sources were reviewed and considered relevant for the scope of this research. A more specific selection of sources was undertaken whilst conducting data analysis. Various databases were consulted such as Scopus, EBSCO host, ScienceDirect and ProQuest. The review was also undertaken based on the following Boolean search categories to facilitate the selection of relevant sources: trends and themes on Corporate Purpose, corporate sustainability and SDGs. Whilst these categories helped us identify relevant themes, the notion of Corporate Purpose itself assisted us in identifying emerging areas of research. Tables 1 and 2 show the search protocol used for this literature review. 
Table 1. Table of Search protocol.

\section{Identification of Databases}

The subject area queried to narrow down the databases was Management within the Business and Economics sub-subject. Multiple databases were searched to avoid biases.

The core databases used were: Scopus, EBSCO host, ScienceDirect, ProQuest. Secondary databases: AIMMAT, Web of Science.

2. Search strategies applied on the databases

Term harvesting: Search vocabulary and terms for the literature review:

Research question: To what extent can the emerging notion of Corporate Purpose be aligned with the SDGs?

Topics: SDGs, Sustainable development, Purposeful Business, business management, purpose/lead strategy, corporate sustainability, leadership.

\begin{tabular}{|c|c|c|}
\hline Keywords & Purposeful Business & Sustainable development goals \\
\hline \multirow[t]{4}{*}{ Synonyms } & Business purpose & -UN SDG compass \\
\hline & Corporate purpose & -UN Global Compact \\
\hline & Purpose-lead Strategy & -Sustainable \\
\hline & & development \\
\hline \multirow[t]{6}{*}{ Concepts related } & -CSR & \\
\hline & -Stakeholder Theory & Global Goals \\
\hline & -Shareholder view & global challenges \\
\hline & -Natural capitalism & \\
\hline & -Mission/led producti & \\
\hline & $\begin{array}{l}\text { Research on purpose, } \\
\text { relationship developm } \\
\text { and accountability. }\end{array}$ & \\
\hline \multirow[t]{2}{*}{ Purpose-led Strategy } & -The purposeful comp & \\
\hline & -Purposeful Business & \\
\hline \multicolumn{3}{|c|}{ 3. Test-run searches, revision of search terms particular to each database, search strategies established. } \\
\hline \multicolumn{3}{|c|}{$\begin{array}{l}\text { 4. Reasons for exclusion: Articles were excluded based on irrelevance to the main subject; (Purpose in Business as a concept, SDGs } \\
\text { in Business); type of publication (Peer review and original studies), language (English). }\end{array}$} \\
\hline
\end{tabular}

Table 2. Source summary.

\begin{tabular}{ccc}
\hline Sources Summary * & \\
\hline Category & Consulted & Reviewed \\
\hline Peer reviewed articles & 80 & 45 \\
Books & 10 & 5 \\
Industry and policy reports & 23 & 10 \\
\hline *
\end{tabular}

The articles cited come from the disciplines of sustainability, economics, management, business ethics, and organizational psychology. This review focuses on conceptual and empirical studies from a constructivist view, as it identifies sources of purpose in management and sustainability literature and existing empirical evidence. The review was completed using Nvivo software for data analysis and it was particularly useful for the data display and review processes.

Once in Nvivo, data was coded according to the core themes of this research, which are: Corporate Purpose, SDGs, Purpose strategy, and SDGs strategy. Figure 1 [7] shows a Nvivo cluster analysis diagram. It highlights relationships amongst themes. For example, it shows the relationship at the strategic level of Corporate-Purpose with Corporate Shared Value (CSV) that in fact, was one of the foundations of our findings. Other subcategories 
were also created from these that were identified from the data to enrich the analysis and draw meaningful conclusions and areas for further research.

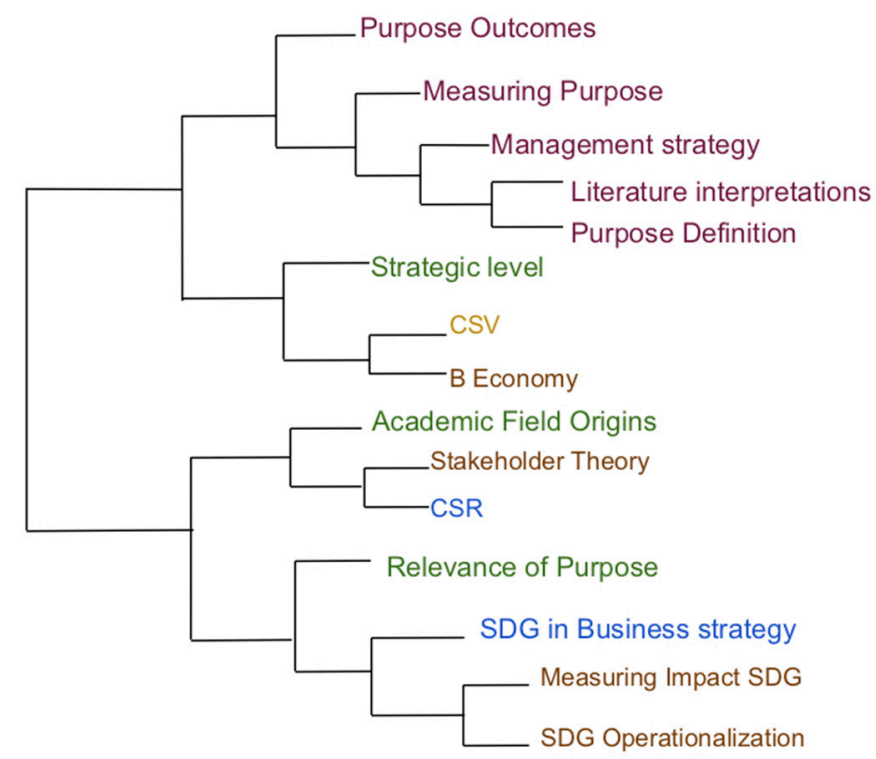

Figure 1. Cluster Analysis of Themes using Nvivo (the Authors, 2021).

\section{Corporate Purpose Review}

This section depicts the drivers that create paradigm-shifts towards a Purposeful Business model. It also explores frameworks and theories on Corporate Purpose emerging from key concepts (see Appendix A) and identifies three approaches to Corporate Purpose: the regulatory-oriented approach, the business-oriented approach and the organizational identity-oriented approach, as well as discusses their features and implications. This review provides an examination of the current understanding of Corporate Purpose as an emerging research agenda that differs from other models to corporate sustainability, such as the triple bottom line, the five capital approach and Corporate Social Responsibility (CSR), among others.

Corporate approaches that follow the triple bottom line model posit economic, environmental, and social spheres as the three core elements to consider when formulating strategies to achieve SDGs. This model has been applied to examine the social and environmental effects of industrial activities. It is argued [33-35] that there is still a gap between the triple bottom line principles and concrete corporate actions to bring these principles into practice. Applying a corporate purpose approach at the core business has the potential to operationalize those principles. The five capitals approach examines SDGs in the light of five forms of capital: natural, human, social, economic, and physical capitals. The premise of the five capital approach is that for long-term sustainability the depletion of one form of capital needs to be compensated by improving or increasing other forms of capital [36]. However, the application of the five capitals approach has been criticized given the often marginal contributions derived from the application of this approach to broader sustainability issues impacting external stakeholders [37]. Corporate Purpose goes beyond the corporation impacting positively on stakeholders [38].

The review also shows that the notion of CSR focuses on premises such as (a) being a "responsible" corporation; (b) compliance with the social and environmental standards; (c) being a good citizen and a generous company $[27,39]$. These premises are not related to the profitable activities of the corporation, rather a cost center activity [27]. Therefore, motivation to be a responsible company is separated from the core business activities. Consequently, CSR practice results exclusively in a trade-off for business and occasionally in redistributions of wealth [27,39]. Academic research [22,40], describes that CSR has played a communicative role in arbitrating corporation and societal relationships with 
fundamental conflict that requires alternative pathways such as Corporate Purpose. Other authors [41,42] stand on a similar perspective highlighting several constraints to create economic value from CSR. Consequently, in practice, CSR's reach is limited to minimum compliance requirements, and is highly related to philanthropy and brand image. In contrast, Corporate Purpose is embedded in the core business of a company to drive societal change determining how companies can make profit by responding to the needs of society.

The operationalization and achievement of the SDGs should embrace other approaches different from CSR. Commitment to the SDGs does not have to do only with minimizing the negative consequences of corporate activities, benefiting few stakeholders and embarking in charitable endeavors under a CSR agenda. Instead, it requires a transformational approach at the core business that can accelerate sustainability integration across the organization [43-49].

In the academic management and sustainability literature, there has been little discussion about the Corporate Purpose concept. Nevertheless, it is a growing term in the management consulting world, for business practitioners and practice-oriented researchers. However, fundamental questions-relating to the underlying culture and assumptions of business that define what the purpose of the corporation is-have a long history and have been extensively debated. In examining Corporate Purpose development, it is clear that debate abounds in the fields of philosophy, economics, corporate governance, and law. The Corporate Purpose concept can be traced back to early 1930 in discussions between shareholders and early stakeholders [50,51].

Since 1970, modern debates demark the emergence of business in society as a research field from multidisciplinary disciplines [52]. Relevant literature lies in discussions around two opposite views. First, the "Friedman doctrine" considers one and just one social purpose of corporations: value maximization for shareholders [53,54]. Second, counter to the shareholder point, the development of the stakeholder theory suggests that the purpose of a corporation is value creation for stakeholders, directly related to the responsibilities a corporation has to all stakeholders $[55,56]$. Other works that acknowledge the relevance to locate Corporate Purpose at the core of business operations have been historical studies on CSR $[57,58]$. While other historical perspectives related to stakeholder theory and ethical interpretations of the firm system theory underlie the roots of corporate purpose [59].

Although influential voices have stood up from both sides, the "Friedman doctrine" is the prevailing paradigm that has shaped business practices, business policy, and business education. This prevailing paradigm has caused business practices that foster growing inequality, environmental degradation, and mistrust [12].

\subsection{Drivers to Corporate Purpose}

A review of the literature shows that Corporate Purpose contributes to modern management doctrines [60] aiming to solve five main corporation failures in today's society $[7,18,61]$ : income inequality and distrust, environmental degradation, technological challenges, intangible nature of companies, and corporate competitiveness.

First, income and wealth inequality are considered to be fueled by corporations [61-63]. The increasing income disparity and continuing low wages has become a glitch in capitalism, producing consequences such as economic stagnation in countries such as the United States' (US) [63]. Similarly, it has been proven that market failures in many sectors increase investor's profits at the expense of social well-being. A growing level of public mistrust in the private sector has intensified in recent years [12,61]. Trust is the basis of the social contract and one of the most important elements for long-term cooperative transitions and interactions; legal contracts and markets cannot work effectively without trust [61,64]. A breach of trust between corporations and the public has occurred due to global scandals that have questioned the legitimacy of the private sector. Scandals such as the Volkswagen emissions violations and fraud in diesel motors pollution measurements in 2014; Lehman Brothers Bank's irresponsible investment in mortgage debt in the US 2008, and accusations 
of the Australia and New Zealand Banking Group's harmful culture of tolerating drugs and strip clubs. For capitalism to survive this trust needs to be repaired. Corporate Purpose addresses this lack of trust which degrades a company's "license to operate" and "social contract". [18,60].

Secondly, environmental degradation caused by corporate activities is driving the decline of natural capital, causing a loss in biodiversity, increasing $\mathrm{CO} 2$ emissions and contributing to the climate crisis. Scientific evidence shows that society has already reached several tipping points in regards to planetary boundaries [65]. The climate crisis is one of the most immediate threats to humankind's existence. The risks that climate change poses to companies have been well identified as representing a disruptive force to undermine business models, however it also represents an opportunity for new perspectives in regulation and governance systems [61]. The "business as usual" approach is no longer feasible due to the current situation of the planet.

Thirdly, technological advances represent challenges for future market dislocations. New technologies management will determine societal problems related with the future of work and disruptions in the competitive landscape [66]. The velocity of technological advances has outpaced regulation to efficiently manage their implications on the broader society. Regulations are far behind the latest technologies and business models and thus, purpose is an opportunity to rethink standard practices and cultural norms to adjust for a new workplace and competitive landscape.

A fourth issue is the changing intangible nature of companies. According to an annual intangible study, [67] assets of global leaders companies have shifted from $83 \%$ tangible (such as, buildings, plant, equipment) to $87 \%$ intangible (such as trademark, patents, intellectual property). This fact not only challenges the shareholders' mindset on managing companies based on ownership of tangible assets but also makes the application of traditional economic tools of competition policy and regulation increasingly irrelevant. Authors such as Smith \& Allee [68] have spotlighted the business management problem of split intangible assets analysis in models and practices that occur alongside tangible assets in processes and transactions [68]. This distinction does not allow a thinking system perspective to measure value networks and the production of value cross corporate networks and supply chains. Corporate Purpose calls to action business management to overcome this problem in value network analysis.

The fifth and final issue has to do with corporate competitiveness. Many business practitioners identify Corporate Purpose and Purposeful Business as strategies to gain a competitive advantage and a form of governance in a high volatile, uncertain, chaotic, and ambiguous environment due to four factors: (1) increased legitimacy and risk management; (2) attracting, retaining, and engaging talent; (3) strong customer and stakeholder relationships, increased employee psychological well being; (4) clear context for daily decision making and business performance. $[3,5,6,69]$. These factors are the main motivation for practitioners to shift to purpose-driven organizations. A survey carried out by Harvard Business Review Analytic Services found that 90\% of 474 [21] executives agree that organizational purpose is important and it should be a priority, but just $46 \%$ mainstream purpose in the strategy and operational decision-making. In those organizations in which purpose is a "driver of strategy and decision-making, executives reported a greater ability to deliver revenue growth and drive successful innovation and ongoing transformation" [21]. Corporate Purpose still needs further research to support the theory that it is not just transforming managerial activity for the common good of society, but is also a core characteristic of healthy, thriving companies.

\subsection{Frameworks and Theories on the Corporate Purpose}

Since 2017 Purposeful Businesses have become more relevant due to the increase in investors' and companies' commitments [61]. There is a dearth in the management and sustainability literature on the function of Corporate Purpose in sustainability management $[3,70,71]$. Yet, it is a growing term across management consulting, business 
practitioners, and practice-oriented researchers [70]. However, there is a long literary history regarding fundamental questions related to the underlying culture and assumptions of businesses that define what the purpose of the corporation is. There is an increasing debate on Corporate Purpose development in philosophy, economics, corporate governance and law fields. Debates can be traced back to the early 1930s, when discussions between shareholder primacy and early stakeholder conceptions took place [50,51].

More recent debates suggest that the notion of Corporate Purpose emerged in 1970 and has longstanding connections with the fields of business and society [52]. The review shows that there are two opposite issues discussed in the literature. First, the "Friedman doctrine" posits that value maximization for shareholders is the only social purpose of corporations [53,54]. This is opposed to the stakeholder theory, which underlines that the purpose of a corporation is value creation for stakeholders and is directly related to the accountabilities that a corporation has to all stakeholders $[53,55,56]$.

Although influential voices have stood up from both sides, the "Friedman doctrine" is the prevailing paradigm that continues to shape business practices, business policy, and business education today. This prevailing paradigm has supported business practices that foster growing inequality, environmental degradation and public mistrust $[13,20,51,62]$. Stakeholder theory fosters a "new set of assumptions about how value is created" [72], where a corporation should also be responsible for creating value for non-shareholders including customers, employees, suppliers, communities and others $[55,56]$. Historically, shareholder view and stakeholder theory discussions provided a comprehensive framework for understanding the basis of Corporate Purpose.

Corporate Purpose is in alignment with stakeholder capitalism, as an alternative view of capitalism. Stakeholder capitalism's objective is to distance itself from traditional underlined values such as self-interest, market competition, and open markets to switch into a capitalism "based on freedom, rights, and the creation by consent of positive obligations" [73]. Therefore, the Corporate Purpose notion shares similar values with stakeholder theory.

\subsubsection{Dimensions of Corporate Purpose}

Although there is not a single one size fits all definition of Corporate Purpose in the managerial context, most definitions coincide that Corporate Purpose goes beyond profit (Appendix A shows a list of definitions found in the literature). Evidence shows two major themes across purpose-related definitions: purpose influences business performance and business should serve society. Findings also show that the Corporate Purpose notion integrates environmental, social, and governance (ESG) factors in the core business. Reviewed definitions also coincide that "purpose" does not have to do with philanthropy or other charitable endeavors, but rather focuses on a company's core operations. This perspective offers a new method to transform business-as-usual to a business strategy that contributes not just to society's well-being but also business legitimacy, public trust, employee engagement, and corporate performance.

A critical review of the literature shows that the notion of Corporate Purpose is a highly heterogeneous concept and can be distinguished by three dimensions: the regulatory-oriented approach; the business-oriented approach; and the organizational identity-oriented approach. See Figure 2. All three views agree that Corporate Purpose is not an end state, rather it is a journey - a starting point - that aligns with five elements (1) "Values" or the principles in which purpose operates; (2) "Vision" an idea of how the future looks like; (3) "Objectives" or corporate key goals; (4) "Strategies" the various initiatives to achieve the objectives; (5) "KPIs" the metrics required to measure progress. Despite such considerations, there is a dearth in the academic literature about approaches to a Corporate Purpose-led strategy. 


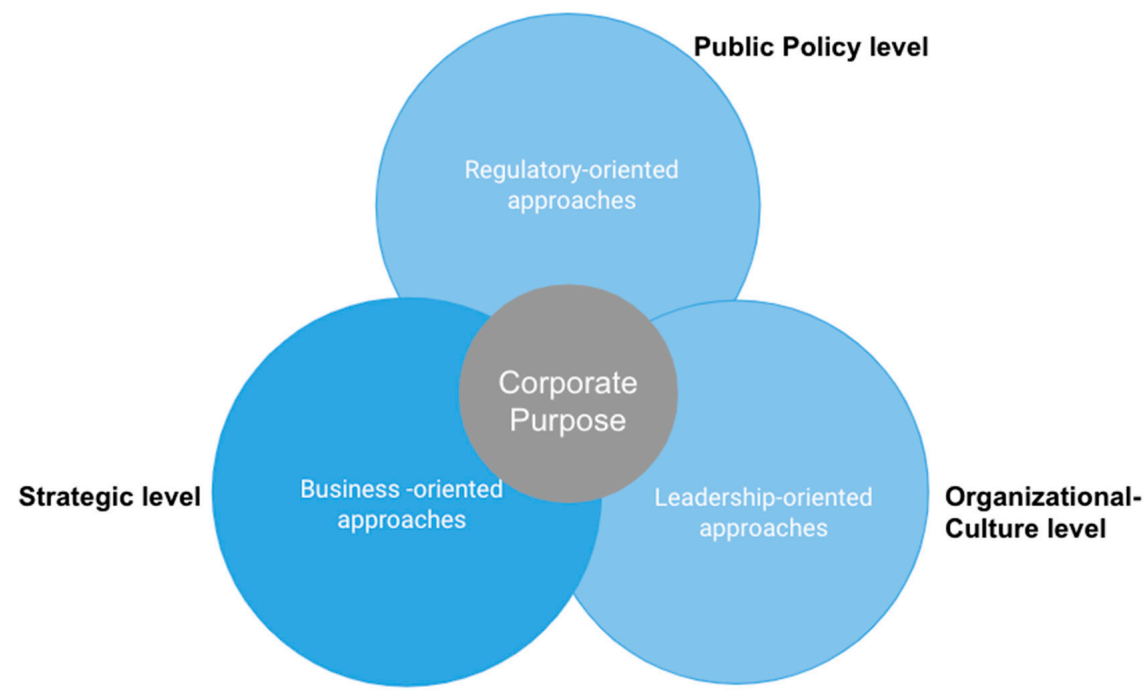

Figure 2. Corporate purpose approaches (the Authors, 2021).

First of all, regulatory-oriented approaches encourage institutional design around purpose and a structural reconceptualization on legal and financial aspects of business $[6,18,67,71]$. Particularly, in concepts such as ownership, governance, performance measurement, and management incentives. In regulatory-oriented approaches, scholars argue that governments should take the lead on legal reform that sets a clear direction towards purposeful business, while the other two approaches focus mainly on shifts inside the corporation leaders and investors forge ahead in applying purpose principles. Secondly, business approaches see corporate purpose as a living strategy to optimize opportunities for developing business model innovations that contribute directly to societal wellbeing while making profitable business. They also focus on long-term revenue maximization.

Thirdly, leadership approaches focus on transforming the organizational culture, drive emotional engagement across employees and main stakeholders, and foster good socio-environmental practices. However, "regulatory approaches" identify the importance of Corporate Purpose as an organizational culture and identity by acknowledging that regulation is difficult to put in place without a culture and values around Corporate Purpose. Therefore, good markets do not make good companies, although good companies make good markets, this is not fixed with regulation.

\subsubsection{Regulatory-Oriented Approach to Purpose}

This approach has gained prominence with The Purposeful Company Task Force (The Task Force) which aims to transform British businesses towards a higher competitive advantage by creating long-term value and meeting social needs. The Task Force published the Purposeful Company-Policy report [18] which counted on the contribution of more than thirty institutions. It gathered evidence linking purpose and performance. For example, it shows evidence that links purpose with higher business performance, estimating an increase in business performance from $6 \%$ to $7 \%$ a year in the British business context [6].

In 2016 the Task Force steering group made four blocks of policy recommendations in the purposeful company policy report. Firstly, company law should include Corporate Purpose statements into articles of association, and introduce new corporate forms. Secondly, increased reporting and accountability which enhances intangible measures and assessment methodologies focusing reporting on long-term value creation. Thirdly, reconceptualization of finances-which includes stimulating a higher flow of equity investments and eliminating impediments for blockholding. Finally, executive remunerations-such as simplifying pay with focus long term equity. The report also shows examples of how companies can be highly successful while also serving the needs of society. 
The Purposeful Company in the UK has created a movement of scholars and practitioners to stimulate the "Purpose" agenda. Programs such as the Future of the Corporation, led by British academic scholars, propose reforming business models for the 21st-century society, so they align with Corporate Purpose compliance. Corporate Purpose aims to produce profitable solutions for people and the planet's problems and does not seek to profit from problem creation or aggravation [61].

Mayer [20] argues for "a radical reinterpretation of the nature of the corporation that centers on Corporate Purpose, its alignment with social purpose, the trustworthiness of companies and the role of corporate culture in promoting purpose and trust" (p. 11). This approach conceives Corporate Purpose from a fundamental standpoint, arguing that businesses should be structured, owned, regulated, and managed in alignment with purpose [74]. It differentiates two concepts of purpose; (1) Social Purpose as desired contributions of companies to society in the production of products and services. (2) Corporate Purpose, defined as the objective actively pursued by corporations in the production of products and services. Advocates of this view pursue an alignment of Corporate Purpose and Social Purpose.

Regulatory approaches consider that Corporate Purpose is the expression of the means by which a business can contribute solutions to societal and environmental problems. Corporate Purpose should create value for both shareholders and stakeholders [61]. In contrast with other perspectives of purpose such as business approaches [11,27] or leadership approaches $[5,75,76]$, the purpose statement is just the first step to re-organize the business around purpose. The purpose statement must be supported by appropriate structures within and outside the corporation. Appropriate structures must be compliant with eight principles. (1) law: adopting a purpose by law; (2) regulation: when purpose is regulated, adopt social license to operate; (3) ownership: encourage shareholders to hold share blocks in the long term; (4) governance: inclusive culture and values to support purpose, (5) measurements: setup metrics that include social and environmental value creation and other non-financial performance; (6) performance should measure goals on both Corporate Purpose and financial performance; (7) finance: rising risk capital should be aligned with purpose from shareholders. Lastly, investments should be made in private and public partnership that facilitates cooperation towards the fulfilment of corporate purposes.

The scope and incentives for managers to define "purpose" depend on policy regulators. Public policymakers have the responsibility to frame and contextualize Corporate Purpose since the fundamental legal framework is currently based on the narrow view of Friedman's interpretation of Corporate Purpose (previously discussed in this article) $[17,20]$.

In practice for companies, Corporate Purpose, first should include social and environmental objectives at the core business activity. Second, it should establish the economic value of these intrinsic goods (such as justice, health, wellness). Third, it should give compliance without socio-environmental harm. Lastly, it should increase the use of better measurements and accountability mechanisms to reduce societal costs on people and the planet [74].

This regulatory stream of Corporate Purpose sparks controversy not just among Corporate Purpose detractors but also other Corporate Purpose views. Recent debates center attention on whether or not Corporate Purpose should focus less on mandatory approaches and more on purpose-lead mindsets, leadership, and corporate strategies within the company. Standpoints that have been clearly made by authors such as $[5,7,11,14]$, amount others locating purpose from a more organizational culture and strategy position to avoid legal compliance.

\subsubsection{Business-Oriented Approach to Purpose}

Business competitiveness and community wellbeing are highly correlated. Companies need successful societies to thrive in the long-term and healthy societies require competitive businesses to thrive as society. Businesses are actively seeking competitive advantages to 
enter emerging markets more efficiently. Using business as a force for good is seen as a way to gain competitive advantage to ensure commercial innovation and profitability.

Corporate Purpose and Purposeful Business have become more prevalent over the last few years in strategy management fields with trend contributions such as Michael Porter and Mark Kramer [27] in the Harvard business review (HBR) article "Creating Shared Value", that coins Purpose as the solution to the current capitalism crisis; pointing to Purpose as the future of capitalism.

This construct is supported by market trends in which increasing social and environmental issues call attention to "unusual business" aiming to address social concerns using a profitable business model [11]. Corporate Purpose is a company's reason for being and helps to solve societal problems, creating significant financial value for the company [11]. The root concept of purpose is Creating Shared Value (CSV) that applies the capitalism model to addresses social issues, creating profits while impacting society in a positive manner and solving global social issues or as CSV motto states "doing well by doing good". CSV advocates argue that the purpose of corporation integrates an unmet societal need, leverages company's assets to create positive change, and strengthens company's competitive position [11].

Shared value is considered a powerful practice to fulfil Corporate Purpose. From this perspective shared value and Corporate Purpose are linked concepts. The purpose must be significant and meet societal needs. It must be authentic and correspond with the culture and the company's DNA and history. The purpose also needs to be profitable as an incentive to constantly innovate on scale. Lastly, purpose must be accountable by reporting initiatives. Corporate Purpose management requires a set of interconnected practices within three areas: strategy, operations and people [11]. Strategically, organizations should identify societal needs to address, examine the business model that best serves the purpose, define how the business creates shared value and for whom, set the goals, and allocate resources to meet purpose. Purpose should be embedded in the operations fostering firstly, open innovation to pivot business models; secondly, public-private alliances; thirdly, suitable measurements and reporting. Finally, purpose should be embedded in people culture, thus organizations need to create structures and roles to fulfil purpose and engage employees and stakeholders around purpose.

The business approach to purpose is grounded on the notions of creating share values. Under this approach Corporate Purpose identifies that capitalism needs strong governments to survive [11]. The traditional view of capitalism without interventions or regulation of governments has been invalidated to build a resilient economy and society to respond to crises [62]. This is a common perception with regulatory approaches of purpose. However, what differs is the profitable nature of purpose, meaning scholars of Corporate Purpose that maintain shared value views argue that companies can also maximize profits by sharing value and fulfilling the corporation purpose. Mayer [13,20], on the contrary, made clear that not always fulfilling the corporation's purpose means maximizing profit pathways.

Corporate purpose is considered a living strategy under this view. A company that has developed its strategy, operations, and culture in alignment with its Corporate Purpose significantly addresses societal and environmental challenges and creates significant financial value for the company. Its purpose must be relevant, meaningful, authentic, profitable, genuine, and accountable. Currently, there is little academic literature on the steps that organizations need to take in order to articulate their purpose [74,77]. However, business leaders intuitively understand the power of addressing social issues using a profitable, scalable business model through a well-defined Corporate Purpose [61].

\subsubsection{Leadership Approaches: Organizational Culture and Sense of Purpose}

We found a clear pattern in the literature that connects Corporate Purpose to corporate identity (see [24,75,76,78,79]). In his work, Hurst [14] introduces the term "purpose economy", focusing on the power of stakeholder engagement to improve companies' per- 
formance and communities' well-being. Other authors $[5,7,14]$ emphasize that "Corporate Purpose" is the foundation for organizational culture.

People and teams with a sense of purpose perform better $[7,71,80]$. These imperatives have brought about the need to define and classify "sense of purpose" in the workplace. Authors $[7,71,80]$ suggest that a sense of purpose is derived from three factors. First, a compelling purpose statement beyond profit, focusing on doing positive actions for others. Second, solid values and culture anchor the Corporate Purpose. Third, stretching goals aligning personal employees' goals with corporate goals.

Similarly, this view presents Corporate Purpose as a distinctive notion that places a particular meaningful inspiration at the core of the company operations [5]. Under this perspective, Corporate Purpose can be better understood through five key elements that define it: (1) it is a meaningful motive as to why a company exists, (2) it is a fundamental attribute of a company identity, (3) it corresponds with long-term economic return, (4) it provides definite guidelines for everyday decision-making process, and (5) it represents a force to motivate and unify relevant stakeholders [5]. Based on a study in the workplace [70], the term Corporate Purpose is mainly related to the meaning of work. Employees feel highly engaged with their job when organizations have a strong Corporate Purpose. For instance, employees actively believe that they are contributing to the community; they feel proud and have a sense of accomplishment to be part of their organization. To nourish and sustain this sense of purpose leadership roles are essential where executives and directors have clear expectations, with an assertive and inspiring lead.

Leadership approaches might also seem similar to business-oriented approaches [27]. However, Corporate Purpose under this approach is not related to the core business or the nature of business activity as it is in business-oriented and regulatory-oriented approaches, respectively. Business-oriented and regulatory-oriented approaches focus on doing good through the business itself, while leadership approaches see Corporate Purpose as a function of employee engagement and, consequently productivity. Leadership approaches start at the pre-strategy level and can be regarded as the motivational bases for Business-oriented approaches.

Research also suggests that in spite of the fact that companies have engaged with the concept, only a few have achieved considerable progress [5]. Many companies have suggested that Corporate Purpose statements are inconsequential, considered to be "cheap talk" [81]. "Purpose washing" is a related term that has become much more prevalent among business practitioners. This notion describes marketing initiatives where a brand claims a commitment to a cause or belief, without this professed commitment being translated into aligned action.

Corporate Purpose is not a marketing strategy. Purpose is rooted in the core business model, corporate strategy, and operations to ensure alignment with corporate goals. This review shows that the major challenge when applying Corporate Purpose to business has to do with finding metrics that help companies identify "purpose washing" [70,82]. To avoid "purpose washing" the literature also shows that Corporate Purpose should be embedded at the governance, performance measurement, and management incentives levels $[13,20,61]$.

\section{Discussion of Sustainable Development Goals and Corporate Purpose Links}

In this section we present a review of the literature that explores the notion of Corporate Purpose and relationships with the SDGs [61]. Grounded on the MDGs, the SDGs are an integrated framework comprising 169 targets and 232 indicators, addressing a high number of concrete topics, such as environmental, diversity, equity, and inclusion targets to end poverty and create a life of dignity and opportunity for all within planetary resources. The SDGs endorse sustainability as the pathway for the future growth of humanity. It takes a comprehensive systematic approach, where sustainability brings balance between meaningful economic growth, environmental wellbeing, and social justice $[8,83]$. The SDGs 
intend to shape public policy, advance science, and mobilize not-for-profit organizations and as well as influence business practices and corporate leadership.

"Business is a vital partner in achieving the SDGs. Companies can contribute through their core activities, and we ask companies everywhere to assess their impact, set ambitious goals and communicate transparently about the results" [23] (p. 4). The SDGs have come to gain relevancy in the business world as corporations demonstrate an increasing willingness to report their commitments in voluntary sustainability reports. For instance, a study on 1141 companies shows [84] that $72 \%$ of companies mentioned the SDGs in their annual corporate or sustainability report in 2018 . Similar results have been discussed by various scholars $[85,86]$. Those efforts are moving at a plodding pace to face the urgency of sustainability challenges and the need for deeper and more serious commitments is paramount: "700 million people are in extreme poverty; 70 million children, women, and men are forcibly displaced; it is needed 202 more years to close the economic gender gap at the current pace; on track for $3.5 \mathrm{C}$ temperature rises this century per current commitments; 8 million metric tons of plastic enter oceans every year; loss of humid tropical primary forests up by $44 \%$ compared to 2002-2013" [87] (p. 4). Having a Corporate Purpose facilitates meaningful contributions to unmet social or environmental needs such as those articulated by the United Nations SDGs $[13,20,61]$.

The SDG framework plan progresses sustainable development in three spheres: economic, social, and environmental, where synergies and trade-offs usually emerge. The persistent trade-offs between economic (profit), social (people), and environmental (planet) are jeopardizing the achievements of the SDGs. Several studies center attention in the tradeoff and synergies between the 17 SDGs and within individual SDG targets [88]. Although these studies brought valuable insights to track the progress and direct policymakers, it does not translate to the business context. This study explores the literature on Corporate Purpose as a transformational approach for helping the private sector overcome trade-offs.

The SDGs business case [23] and "Corporate Purpose" - in both regulatory and business oriented approaches-promotes the use of business as a force for good and reimagines the role of the corporation in the future of workplaces and sustainable societies. The United Nations endorsed global challenges such as the SDGs as market opportunities for innovative companies that can provide global solutions [23]. Unexplored business models embracing new technologies, processes, and services that benefit sustainable development will redirect global public and private capital flows towards SDGs operationalization.

This review suggests that although all three perspectives of Corporate Purposeregulatory-oriented, business-oriented and leadership-oriented—strongly align with SDGs, the business-oriented approach is the most viable approach to promote the action of the SDGs in a more immediate manner. Together the SDGs and Corporate Purpose frameworks shift traditional perspectives from being reactive to stakeholders' mandates to a proactive action, where companies play an active role in influencing the sustainable development trajectories.

The review shows that SDGs 13,12 , and 8 are the most common priority goals for business, with $61 \%$ globally of businesses identifying Climate Action (SDG 13) as a priority. However, while the number of companies committing to the SDGs is increasing, these statements are not always matched in practice, and we need to see more affirmative action if significant progress is to be achieved [23].

Regulatory-oriented approaches, for example, indicate that the challenges articulated through the SDGs and concerns around trust, globalization, and rapid technological change are the drivers for transforming companies to purpose-led companies [13]. Grounded on the company's capabilities, evidence on business-oriented approaches to purpose shows that companies should first identify priority SDGs, second, design a corporate strategy in alignment with the SDGs, and third, implement the strategy whilst leveraging the SDGs [61]. Although, in reviewing the literature, no data was found on the direct association between leadership-oriented approaches and SDGs, leadership-oriented approaches strongly recommend engaging with social and environmental projects outside the company to enhance "sense of purpose" in the workplace [5,14]. 
The results of this review show that Corporate Purpose is a sustainability approach to action the SDGs. We conclude that although all three approaches to Corporate Purpose contribute to the progress of the SDG agenda, the business-oriented approach has a more immediate positive effect in actioning the SDGs. The strategic level of Corporate Purpose can facilitate not just the SDGs' advocacy but also concrete procedures to achieve its targets. Business-oriented approaches provide a particular focus on practicing Corporate Purpose within a company to guide all core business decisions as shown in (Figure 3). This shows how the three approaches interact within the corporate environment and capabilities. Displaying where the Corporate Purpose approach can potentially impact the corporation the most: outside the business (business ecosystems, e.g., corporate law), inside the business (e.g., everyday operations), soft skills (e.g., brand image, culture), core skills (corporate strategy, business model).

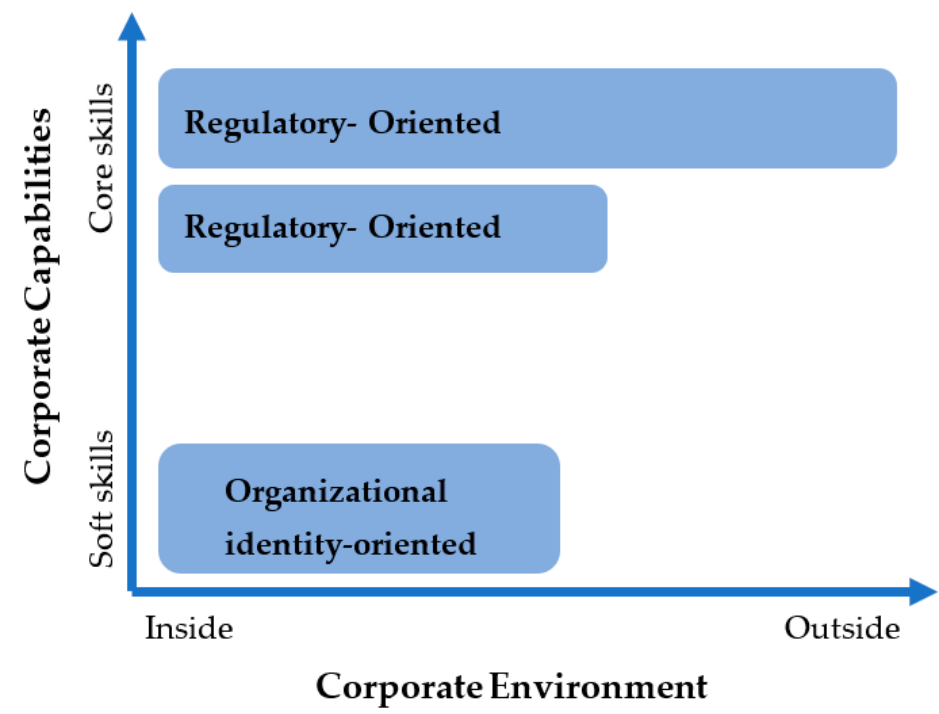

Figure 3. Focus areas of the Corporate Purpose dimensions (the authors, 2021).

Thus, the main findings suggest that in general, Corporate Purpose has more material effects under the business-oriented approaches; which in turn better stimulates the SDG agenda. For instance, by aligning business-oriented approaches to purpose with the SDGs, corporate leaders have clear incentives to redirect investment flows in a manner that maximizes value creation and opportunities to foster sustainable development [89]. The strategic level overcomes the tension between business strategy and societal development that companies face when applying the SDGs [90]. Corporate Purpose also overcomes issues concerning the integration of sustainability into business strategies, not as a compliment, but rather as conception disseminated in all business operations and decisions.

Although the potential of regulatory-oriented approaches to create a more ambitious and meaningful contribution to the SDG agenda is indisputable, its operationalization is less viable. Regulatory-oriented approaches require incremental, transformational changes to fully integrate Corporate Purpose through legal avenues, which in turn represent a dramatic disruption in the business landscape. Thus, the normative effects of Corporate Purpose as disruptive innovation will require exceptional political leadership and cross-sector synergy. More academic scholarship needs to be done to rigorously explore Corporate Purpose as disruptive innovation at the policy level. Therefore, considering that only ten years remain to action the SDG agenda, a regulatory-oriented approach to Corporate Purpose cannot feasibly achieve this objective within this timeframe.

This analysis reveals that Corporate Purpose builds the casual conditions for a shift towards a sustainable economy in the which the way companies prioritize the value creation for stakeholders ties-in the SDGs more organically. It suggests that Corporate Purpose fosters the creation of long-term profitable businesses and supports the incorpo- 
ration of sustainable goals in business operations. Similarly, studies revised indicate that the constructs of Corporate Purpose and Corporate Sustainability are largely congruent and complementary. On a theoretical level Corporate Purpose is a distinct approach to Corporate Sustainability—same ultimate ends, different ultimate means [5]. Corporate Sustainability is defined as an organization's approach to creating value in the short- and long-term without compromising the ability of future generations to meet their own needs as well as the coexistence of the biosphere and human civilization [91,92].

\section{Conclusion: Corporate Purpose as an Approach to Action the SDGs}

This review identified Corporate Purpose as an emerging research agenda to address today's for-profit organizational sustainability challenges. The Corporate Purpose of a company is its reason for existence. It determines a company's goals and defines its meaning and contribution to society $[18,61]$. It represents an organizational transformation that helps corporations transcend the flaws of capitalism, transition to sustainable economies, and operationalize the SDGs effectively.

Corporate Purpose could potentially be the engine to mobilize the $75 \%$ of the global GDP that the private sector represents $[93,94]$ towards more sustainable business practices. The review analysis shows three major ways in which Corporate Purpose contributes to actioning the SDGs. Firstly, Corporate Purpose eliminates the traditional tension between profit maximization and societal benefit that companies generally face when applying sustainability strategies. This is because Corporate Purpose incorporates social purpose into core business activity.

Secondly, Corporate Purpose does more than just communicate a company's commitment to the SDGs externally, it guides the evolution of strategies, priorities, and decisionmaking within the company, thus increasing the likelihood of creating long-term sustainable impact. Thirdly, Corporate Purpose allocates SDGs priorities at management level by promoting tools to action the SDGs such as the "SDG action manager" [95] and the "Future-Fit Business" [61]. These two instruments are sustainability management tools for companies to track action on the SDGs in alignment with their Corporate Purpose. These are also for investors to easily access, measure, and manage the impact of their activities and serve as a mechanism to directly link SDGs targets with the Corporate Purpose of an organization.

This literature review has also revealed that Corporate Purpose is a mechanism to operationalize and action the SDGs commitments within the company. From an internal perspective, such operationalization directs strategy, sets priorities, and informs decisionmaking. Externally, it shows to the public a corporation commitment. It also works as a call to action for organizational change, it is not an end state, rather it is the starting point of a journey that requires an alignment with five elements (1) values that are the principles that will be the framework in which purpose operates and becomes organizational culture; (2) vision which is a picture in words that depict the future; (3) objectives which are the intentions and key goals; (4) strategies which are various initiatives to achieve the objective; and (5) key performance indicators to measures progress [89]. In practice, this agenda would first, understand the value created and for whom, second, codify the purpose, third, create a vision for a purposeful future and lastly, design a purpose-led strategy to realize the vision [96]. Despite such considerations, in academic literature, little has been published regarding the theoretical approach to a Corporate Purpose-led strategy in the private sector.

This study has identified the main drivers for companies to become purposeful companies and use Corporate Purpose to transform for-profit organizations for the 21st Century society. The drivers identified are: (1) public distrust and income inequality which jeopardize corporate legitimacy [64,97]; (2) environmental degradation which is threatening humankind's existence as we know it and suggests value creation within planetary boundaries [19]; (3) technological advances that represent opportunities but also challenges in terms of market dislocation and transitions to future workplace [98]; 
(4) the intangible nature of companies that demand innovation in the current context of governance and finances [54].

Putting purpose at the heart of corporations and into companies' core operations will restore trust and mitigate the side effects of technological advances and disruptive changes. It will reconcile the trade-off between profits, people, and the planet as well as foster the modernization of corporate finance measurements [96].

Most importantly the data from this article demonstrates that Corporate Purpose strategy facilitates the transition to sustainable operations. These factors make a strong case for change towards a Corporate Purpose Model. Corporate Purpose strategy provides companies focus to direct operations, strategies and decision making. Corporate Purpose is not the company's vision and mission [10]. It describes why a company exists. In contrast, the vision is a picture in words about what fulfilling a company's purpose will look like at a designed time in the future, while the mission corresponds to what a company does [27]. For example, ING bank has a purpose to empower people to stay a step ahead in life and in business [99]. A vision to provide customers with the most effective solutions to help them best manage their financial futures while creating long-lasting value for all stakeholders $[27,96]$. Its mission is to be the preferred bank of customers through operational excellence and international service quality; and for employees to have the highest level of ethical and moral values.

The literature review demonstrates that Corporate Purpose is a social construction, which is highly adaptable, veering, and substitutable depending on the thought stream. The results indicate that the existing frameworks that an adequately articulated Corporate Purpose framework can build on are stakeholder management [100], the shared value approach [27], organizational purpose [5], and the future of the corporation approach [61]. Considering these existing frameworks three themes emerge from the studies discussed that was named "Dimensions of Corporate Purpose".

This finding, while preliminary, suggests a taxonomy of Corporate Purpose research that surged from the qualitative analysis of this review. The analysis revealed three dimensions of Corporate Purpose. They are the regulatory-oriented approaches, businessoriented approaches, and organizational culture-oriented approaches (See Figure 2). Regulatory-oriented approaches refer to management academic streams where Corporate Purpose is located at the public policy level. Studies highlight the leading role of policy makers to create the legal framework in which the Corporate Purpose can set its foundations. $[13,20,101]$. Suggesting, therefore, that Corporate Purpose should have normative effects. Although authors recognized the need for corporations to embed their Corporate Purpose in the company's strategy, operations, and corporate culture, studies suggest legal avenues are the most viable method of reforming a corporation's structures. Reforms are required to eliminate or mitigate existing barriers for the real practice of Corporate Purpose beyond profits [102].

The business-oriented approach, on the other hand, refers to the stream of thought that perceives Corporate Purpose at the strategic level and promotes long-term revenue maximization. From a business model innovation perspective, it looks actively to optimize opportunities [103-106] for business that generate a material benefit to overcome a societal or environmental challenge while still making a profitable revenue. The results of this review show that Corporate Purpose is a sustainability approach to action the SDGs. We conclude that although all three approaches to Corporate Purpose contribute to the progress of the SDG agenda, the business-oriented approach has a more immediate positive effect in actioning the SDGs. The strategic level of Corporate Purpose can facilitate not just the SDGs' advocacy but also concrete procedures to achieve its targets, such as a Purpose-led strategy. Business-oriented approaches provide a particular focus on practicing Corporate Purpose within a company to guide all core business decisions. 


\section{Future Research}

This article presented a critical review of the literature on Corporate Purpose, a highly heterogeneous concept that can be distinguished by three dimensions: the regulatoryoriented approach; the business-oriented approach; and the organizational identity-oriented approach. The review also suggests how the purpose-led strategy has the potential to support corporations in the transition to meet the SDGs; and how Purposeful Business can serve as an innovation in the strategic management field. More evidence-based research and open exchange contributions are required to scientifically examine the role that Purposeful Business can play in solving both corporation failures and sustainable development trajectories. The stewardship and agency of influential leaders is essential to mobilize the paradigm shift and translate the appetite of the public conversation about Corporate Purpose to a more knowledge-based, established practice.

The research shows a dearth in the literature on the process of how companies can articulate their own purpose within all levels of organization [20]. This study has raised questions about the need for scholarly development on Corporate Purpose-led strategy in the strategic management field [70], further empirical evidence [61], and conceptual development on Corporate Purpose and corporate strategy. This study was limited by the absence of the Corporate Purpose-led strategy concept in academic literature that could have significant implications for the progress of the SDGs across business operations and the leadership of the private sector in the achievement of the SDGs.

Together these results provide important insights into a resurgence of academic interest in the constructive role of Corporate Purpose in organizations and distinguish the current mainstream fronts: legal, strategic, and organizational culture. However, Corporate Purpose has little empirical evidence in the strategic management field [70] and further conceptual clarity is needed. Significant opportunities for future research were identified in this article to ensure that studies on Corporate Purpose move to the center of strategy research. Below a range of indicative research questions for future investigations are presented:

\section{Future Research Questions}

- What are the determinants of a Corporate Purpose-led strategy?

- How can a Corporate Purpose-led strategy be built and articulated in an organization?

- How is the Corporate Purpose-led strategy related to building stakeholder relationships and increasing employee engagement and productivity?

- What are the processes and mechanisms that need to be in place to operationalize a Corporate-Purpose-led strategy?

- How can Purposeful Business become the norm and which legal pathways are required to incentivize Corporate Purpose-led strategies in corporations?

- How does Corporate Purpose relate to other concepts in academic literature?

- What is the role of business schools to boost a broader vision of Corporate Purposeled strategy?

- How can a Corporate Purpose-led strategy facilitate competitive advantage in markets, competition, and business management?

One of the more significant findings to emerge from this study is that Corporate Purpose effectively integrates the sustainability agenda and embeds it into the core foundation of an organization. It contributes to the modernization of corporations to shift from a "business as usual" mentality, which perceives sustainability as an externality, to incorporate the SDGs and general sustainability factors in the company's underlying purpose. We evaluated the implications of Corporate Purpose on the operationalization of the SDGs. The results showed that out of the three Corporate Purpose approaches, the business approach is most effective in addressing the urgency of operationalizing the SDGs.

Although the main change agents that are leading the current landscape of Corporate Purpose-regulatory, business, and organizational oriented perspectives-are related, overlapping, and interconnected, they do not have a common theoretical ground and in some cases seem to be disconnected works that lack compatibility. Therefore, we recommend 
that future research into Corporate Purpose as a business strategy be undertaken to build upon what was presented in this article. We contributed to the sustainability and strategy management field by mapping, in a systematic manner, all current efforts to activate Corporate Purpose and provided a synthesized perspective to inform future research and motivate business practitioners to contribute to the SDGs and sustainable development by employing a Corporate Purpose-led strategy.

Author Contributions: D.J.: Conceptualization, Methodology, Data Collection and Analysis, Validation, Writing; I.B.F.: Conceptualization, Research Design, Methodology, Data Analysis; Supervision, Visualization, Validation, Writing Review \& Editing; T.S.: Writing—Review \& Editing. All authors have read and agreed to the published version of the manuscript.

Funding: This research received no external funding.

Institutional Review Board Statement: Not applicable.

Informed Consent Statement: Not applicable.

Data Availability Statement: Not applicable.

Acknowledgments: This article builds on work done by "People with Purpose" a purpose-led consulting company based in Brisbane Australia that specializes in equipping businesses and leaders to become more resilient and impactful. We thank Danielle Duell for her inputs, comments and ideas on this piece of research. Her pioneer work in the industry has helped companies make profit purposefully, leading the implementation of Purpose in corporate governance for a sustainable future of the enterprise.

Conflicts of Interest: The authors declare no conflict of interest.

\section{Appendix A}

Table A1. A list of definitions found in the literature

\begin{tabular}{cc}
\hline \multicolumn{1}{c}{ Author } \\
\hline World Economic Forum (2020)
\end{tabular}

Porter \& Kramer 2011 (2020)

The purpose of a company is to engage all its stakeholders in shared and sustained value creation. In creating such value a company serves not only its shareholders, but all its stakeholders-employees, customers, suppliers, local communities, and society at large.

The purpose of a great company is its reason for being. It defines its existence and contribution to society. It determines its goals and strategy.

Defines a Corporate Purpose that integrates an unmet societal need, leverages your company's assets to create positive change, and strengthens your company's competitive position. Businesses' role in society

Management Institute and

Blueprint for better business (2018)

An organization's meaningful and enduring reason to exist that aligns with long-term financial performance, provides a clear context for daily decision making, and unifies and motivates relevant stakeholders

Hollensbe et al. (2014)

Defined purpose as the reason for which business is created or exists, its meaning and direction

Thakor and Quinn (2013)

"Higher purpose" of the organization that "is perceived as producing a social benefit over and above the tangible pecuniary payoff that is shared by the principal and the agent" (p. 2)

Steen (2015)

Defined corporate purpose broadly as "a concrete goal or objective for the firm that reaches beyond profit maximization"

Gartenberg et al. (2016)

Defined corporate purpose "as the meaning of a firm's work beyond quantitative measures of financial performance"

Doined the term "purpose economy" to describe the new context and ways in which people and organizations are focused on creating value. In his words, purpose economy is "an economy where the value lies in establishing a purpose for employees and

Hurst (2014) customers-through serving needs greater than their own, enabling personal growth, and building community" (Hurst, 2014, p. 22)

HBR and EY (2015)

Defined organizational purpose as "an aspirational reason for being which inspires and provides a call to action for an organization and its partners and stakeholders and provides benefit to local and global society." 


\section{References}

1. Chouinard, Y.; Ellison, J.; Ridgeway, R. The sustainable economy. Harv. Bus. Rev. 2011, 89, 52-62.

2. Rubio-Mozos, E.; García-Muiña, F.; Fuentes-Moraleda, L. Rethinking 21st-Century Businesses: An Approach to Fourth Sector SMEs in Their Transition to a Sustainable Model Committed to SDGs. Sustainability 2019, 11, 5569. [CrossRef]

3. Henderson, R.; Steen, E.V.d. Why Do Firms Have "Purpose"? The Firm's Role as a Carrier of Identity and Reputation. Am. Econ. Rev. 2015, 105, 326-330. [CrossRef]

4. Henderson, D. The Role of Business in the Modern World; Institute of Economic Affaires: London, UK, 2004.

5. Hurth, V.; Ebert, C.; Prabhu, J. Organisational Purpose: The Construct and Its Antecedents and Consequences. Available online: https://ideas.repec.org/p/jbs/wpaper/201802.html (accessed on 23 March 2021).

6. Big Innovation Centre. The Purposeful Company_Policy Report; Big Innovation Centre: London, UK, 2017.

7. Murray, K. People with Purpose: How Great Leaders Use Purpose to Build Thriving Organizations; Kogan Page Publishers: London, UK, 2017.

8. Franco, T.; Chatterji, T.; Derbyshire, E.; Tracey, J. Actioning the Global Goals for Local Impact: Towards Sustainability Science, Policy Education and Practice; Springer: Singapore, 2020.

9. Cordova, M.F.; Celone, A. SDGs and Innovation in the Business Context Literature Review. Sustainability 2019, 11, 7043. [CrossRef]

10. Graham, K. Your company's purpose is not its vision, mission, or values. Harv. Bus. Rev. 2014, 3, $285-306$.

11. Eckert, G.S.B. Purpose Playbook: Putting Purpose into Practice with Shared Value; 2020. Available online: https://www. sharedvalue.org/purpose-playbook/ (accessed on 23 March 2021).

12. Mayer, C. Who's responsible for irresponsible business? An assessment. Oxf. Rev. Econ. Policy 2017, 33, 157-175. [CrossRef]

13. Mayer, C. Prosperity: Better Business Makes the Greater Good; Oxford University Press: Oxford, UK, 2018.

14. Hurst, A. The Purpose Economy, Expanded and Updated: How Your Desire for Impact, Personal Growth and Community is Changing the World; Elevate Publishing: Boise, ID, USA, 2016.

15. Hsieh, N.-H.; Lange, B.; Rodin, D.; Wolf-Bauwens, M.L. Getting clear on corporate culture: Conceptualisation, measurement and operationalisation. J. Br. Acad. 2018, 6, 155-184. [CrossRef]

16. Dhanesh, G.S. Who cares about organizational purpose and corporate social responsibility, and how can organizations adapt? A hypermodern perspective. Bus. Horiz. 2020, 63, 585-594. [CrossRef]

17. Hsieh, N.-H. The Social Contract Model of Corporate Purpose and Responsibility. Bus. Ethic-Q. 2015, 25, 433-460. [CrossRef]

18. Big Innovation Centre. The Purposeful Company: Interim Report; Big Innovation Centre: London, UK, 2016.

19. Sjåfjell, B. Sustainable Value Creation within Planetary Boundaries-Reforming Corporate Purpose and Duties of the Corporate Board. Sustainability 2020, 12, 6245. [CrossRef]

20. Mayer, C. The future of the corporation: Towards humane business. J. Br. Acad. 2018, 1-16. [CrossRef]

21. Harvard Business Review Analytic Services. The Business Case for Purpose. Harvard Business Review Analitics Services Report; Harvard University: Cambridge, MA, USA, 2015.

22. Hsieh, N.-H.; Meyer, M.; Rodin, D.; ven't Klooster, J. The Social Purpose of Corporations. J. Br. Acad. 2018, 6, 49-73. [CrossRef]

23. WBCSD. The Guide for Business Action on the SDGs; World Business Council for Sustainable Development (WBCSD): Geneva, Switzerland, 2015.

24. Logan, G.M. Loyalty and a Sense of Purpose. Calif. Manag. Rev. 1984, 27, 149-156. [CrossRef]

25. Abe, M.; Franco, I. Socially Responsible Business: A Model for a Sustainable Future; UNESCAP: Bangkok, Thailand, 2017.

26. Raworth, K. A Safe and Just Space for Humanity: Can We Live within the Doughnut; Oxfam: Oxford, UK, 2012 ; Volume 8, pp. 1-26.

27. Porter, M.E.; Kramer, M.R. Creating shared value. In Managing Sustainable Business; Springer: Berlin/Heidelberg, Germany, 2019; pp. 323-346.

28. United Nations Global Compact. SDG Bonds I Leveraging Capital Markets for the SDGs; United Nations Global Compact: New York, NY, USA, 2019.

29. Webster, J.; Watson, R.T. Analyzing the past to prepare for the future: Writing a literature review. MIS Q. 2002, 26, xiii-xxiii.

30. Tranfield, D.; Denyer, D.; Smart, P. Towards a Methodology for Developing Evidence-Informed Management Knowledge by Means of Systematic Review. Br. J. Manag. 2003, 14, 207-222. [CrossRef]

31. Denyer, D.; Tranfield, D. Using qualitative research synthesis to build an actionable knowledge base. Manag. Decis. 2006, 44, 213-227. [CrossRef]

32. Jørgensen, U. Grounded theory: Methodology and theory construction. Int. Encycl. Soc. Behav. Sci. 2001, 1, 6396-6399.

33. La Bonne, B. The mining industry and the community: Joining forces for sustainable social development. Nat. Resour. Forum 1999, 23, 315-322. [CrossRef]

34. Jenkins, H.; Yakovleva, N. Corporate Social Responsibility in the Mining Industry: Exploring Trends in Social and Environmental Disclosure. J. Cleaner Prod. 2006, 14, 271-284. [CrossRef]

35. Franco, I. Building Sustainable Communities: Enhancing Human Capital in Resource Regions. Ph.D. Thesis, The University of Queensland, Brisbane, QLD, Australia, 2014.

36. Porritt, J. Capitalism as If the World Matters; Cromwell Press: Trowbridge, UK, 2007.

37. Brereton, D.; Pattenden, C. Measuring what Matters: Monitoring the Contribution of a New Mining Project to Community Sustainability. In Proceedings of the 3rd International Conference on Sustainable Development Indicators in the Minerals Industry, Milos Island, Greece, 17-20 June 2017. 
38. Edmans, A. Grow the Pie: How Great Companies Deliver Both Purpose and Profit; Cambridge University Press: Cambridge, UK, 2020.

39. Porter, M.E.; Kramer, M.R. Strategy and society: The link between competitive advantage and corporate social responsibility. Harv. Bus. Rev. 2006, 84, 78-92.

40. David, R. Make purpose Operational. J. Br. Acad. 2018, 10. [CrossRef]

41. Barnett, M.L. The Business Case for Corporate Social Responsibility: A Critique and an Indirect Path Forward. Limits Stakehold. Influ. 2018, 228-251. [CrossRef]

42. Glauner, F. The Myth of Responsibility: On Changing the Purpose Paradigm. Humanist. Manag. J. 2018, 4, 5-32. [CrossRef]

43. Pirson, M.; Turnbull, S. Complexity Theory, CSR, and Corporate Governance-The Need for Alternative Governance Models. SSRN Electron. J. 2012. [CrossRef]

44. Crane, A.; Palazzo, G.; Spence, L.J.; Matten, D. Contesting the value of "creating shared value". Calif. Manag. Rev. 2014, 56, 130-153. [CrossRef]

45. Waddock, S. Parallel Universes: Companies, Academics, and the Progress of Corporate Citizenship. Bus. Soc. Rev. 2004, 109, 5-42. [CrossRef]

46. Frederick, W.C. Moving to CSR: What to Packfor the Trip. Bus. Soc. 1998, 37, 40-59. [CrossRef]

47. Matten, D.; Moon, J. "Implicit" and "explicit" CSR: A conceptual framework for a comparative understanding of corporate social responsibility. Acad. Manag. Rev. 2008, 33, 404-424. [CrossRef]

48. Frynas, J.G. The false developmental promise of corporate social responsibility: Evidence from multinational oil companies. Int. Aff. 2005, 81, 581-598. [CrossRef]

49. Elving, W.J.; Golob, U.; Podnar, K.; Nielsen, A.E.; Thomson, C. The bad, the ugly and the good: New challenges for CSR communication. Corp. Commun. Int. J. 2015, 20, 118-127. [CrossRef]

50. Berle, A.A. For Whom Corporate Managers Are Trustees: A Note. Harv. Law Rev. 1932, 45, 1365-1372. [CrossRef]

51. Stout, L.A. The Shareholder Value Myth: How Putting Shareholders First Harms Investors, Corporations, and the Public; Berrett-Koehler Publishers: Oakland, CA, USA, 2012; Incorporated.

52. Waddock, S.; Lee, J. The Sustainability and Popularity Paradoxes of SIM Scholarship. In Business and Society 360; Emerald: Bingley, UK, 2020; pp. 215-236.

53. Friedman, M. Capitalism and Freedom; (First Published, 1962); University of Chicago Press: Chicago, IL, USA, 1982.

54. Henderson, D. Misguided Virtue: False Notions of Corporate Social Responsibility; New Zealand Business Roundtable: Wellington, New Zealand, 2001.

55. Freeman, R.E.; Wicks, A.C.; Parmar, B. Stakeholder theory and "the corporate objective revisited". Organ. Sci. 2004, 15, 364-369. [CrossRef]

56. Donaldson, T.; Preston, L.E. The stakeholder theory of the corporation: Concepts, evidence, and implications. Acad. Manag. Rev. 1995, 20, 65-91. [CrossRef]

57. Coronella, S.; Caputo, F.; Leopizzi, R.; Venturelli, A. Corporate social responsibility in Economia Aziendale scholars' theories. Med. Account. Res. 2018, 26, 640-656. [CrossRef]

58. Signori, S.; Rusconi, G. Ethical thinking in traditional Italian Economia Aziendale and the stakeholder man-agement theory: The search for possible interactions. J. Bus. Ethics 2009, 89, 303-318. [CrossRef]

59. Rusconi, G. Ethical Firm System and Stakeholder Management Theories: A Possible Convergence. Eur. Manag. Rev. 2018, 16, 147-166. [CrossRef]

60. Millstein, I.; Gordon, J.; Gilson, R.; Mayer, C.; Bresnahan, K.; Lipton, M. Session I: Corporate Purpose and Governance. J. Appl. Corp. Financ. 2019, 31, 10-25. [CrossRef]

61. Mayer, C. Principles for Purposeful Business: How to Deliver the Framework for the Future of the Corporation: An Agenda for Business in the 2020s and beyond; British Academy Future of the Corporation Programme: London, UK, 2019.

62. Collier, P. The Future of Capitalism: Facing the New Anxieties; Penguin: London, UK, 2018.

63. Bell, S.; Keating, M. Low Wage Growth: Why It Matters and How to Fix It. Aust. Econ. Rev. 2019, 52, 377-392. [CrossRef]

64. Huang, Y.; Wilkinson, I.F. The dynamics and evolution of trust in business relationships. Ind. Mark. Manag. 2013, 42, 455-465. [CrossRef]

65. Steffen, W.; Richardson, K.; Rockström, J.; Cornell, S.E.; Fetzer, I.; Bennett, E.M.; Biggs, R.; Carpenter, S.R.; De Vries, W.; De Wit, C.A.; et al. Planetary boundaries: Guiding human development on a changing planet. Science 2015, 347, 1259855. [CrossRef]

66. Porter, M.E.; Heppelmann, J.E. How smart, connected products are transforming companies. Harv. Bus. Rev. 2015, 93, 96-114.

67. Tomo, O. Annual Study of Intangible Asset Market Value; Ocean Tomo, LLC: Chicago, IL, USA, 2015.

68. Smith, P.A.; Allee, V. Value-Creating Networks: Organizational Issues and Challenges. In The Learning Organization; Emerald: Bingley, UK, 2009.

69. Ye, L. Corporate purpose performance as a driver of employee engagement: The mediating role of transformational leadership and job resources. In School of Management, Economics, Law, Social Sciences and International Affairs; University of St. Gallen: St. Gallen, Switzerland, 2019.

70. Gartenberg, C.M.; Prat, A.; Serafeim, G. Corporate Purpose and Financial Performance. Organ. Sci. 2018, 30, 1-18. [CrossRef]

71. Hollensbe, E.; Wookey, C.; Hickey, L.; George, G.; Nichols, C.V. Organizations with Purpose. Acad. Manag. J. 2014, 57, 1227-1234. [CrossRef]

72. Freeman, R.E.; Martin, K.; Parmar, B. Stakeholder Capitalism. J. Bus. Ethics 2007, 74, 303-314. [CrossRef] 
73. Wicks, A.C.; Harrison, J.S.; Freeman, R.E. Stakeholder Theory: The State of the Art; Cambridge University Press: Cambridge, UK, 2010.

74. Available online: https://www.thebritishacademy.ac.uk/publishing/review/34/british-academy-review-34-make-purposeoperational/ (accessed on 23 March 2021).

75. Snook, S.A.; Ellsworth, R.R. Leading with Purpose: The New Corporate Realities. Acad. Manag. Rev. 2003, 28, 675. [CrossRef]

76. Bartlett, C.A.; Ghoshal, S. Changing the role of top management: Beyond strategy to purpose. Harv. Bus. Rev. 1994, 72, 79-88.

77. Gratton, L. Living Strategy: Putting People at the Heart of Corporate Purpose; FT Press: Upper Saddle River, NJ, USA, 2000.

78. Jordi, C.L. Rethinking the firm's mission and purpose. Eur. Manag. Rev. 2010, 7, 195-204. [CrossRef]

79. Sisodia, R.S.; Wolfe, D.B.; Sheth, J.N. Firms of Endearment: The Pursuit of Purpose and Profit; Wharton School Publishing: Upper Saddle River, NJ, USA, 2007.

80. Barrick, M.; Mount, M.; Li, N. The Theory of Purposeful Work Behavior: The Role of Personality, Higher-Order Goals, and Job Characteristics. Acad. Manag. Rev. 2013, 38, 132-153. [CrossRef]

81. Guiso, L.; Sapienza, P.; Zingales, L. The value of corporate culture. J. Financ. Econ. 2015, 117, 60-76. [CrossRef]

82. Gartenberg, C.M.; Serafeim, G. Corporate Purpose and Firm Ownership. SSRN Electron. J. 2019. [CrossRef]

83. Franco, I.; Saito, O.; Vaughter, P.; Whereat, J.; Kanie, N.; Takemoto, K. Higher education for sustainable development: Actioning the global goals in policy, curriculum and practice. Sustain. Sci. 2018, 14, 1621-1642. [CrossRef]

84. PWC. SDG Reporting Challenge 2019; PriceWaterhouseCoopers: London, UK, 2019.

85. Avrampou, A.; Skouloudis, A.; Iliopoulos, G.; Khan, N. Advancing the Sustainable Development Goals: Evidence from leading European banks. Sustain. Dev. 2019, 27, 743-757. [CrossRef]

86. Thorlakson, T.; De Zegher, J.F.; Lambin, E.F. Companies' contribution to sustainability through global supply chains. Proc. Natl. Acad. Sci. USA 2018, 115, 2072-2077. [CrossRef]

87. United Nations Global Compact. SDG Ambition Scaling Business Impact for the Decade of Action REPORT. A United Nations Global Compact Partnership with Accenture and SAP. 2020. Available online: https://www.unglobalcompact.org/library/5732 (accessed on 23 March 2021).

88. Kroll, C.; Warchold, A.; Pradhan, P. Sustainable Development Goals (SDGs): Are we successful in turning trade-offs into syn-ergies? Palgrave Commun. 2019, 5, 1-11. [CrossRef]

89. El Alfy, A.; Palaschuk, N.; El-Bassiouny, D.; Wilson, J.; Weber, O. Scoping the Evolution of Corporate Social Responsibility (CSR) Research in the Sustainable Development Goals (SDGs) Era. Sustainability 2020, 12, 5544. [CrossRef]

90. Vildåsen, S.S.; Keitsch, M.; Fet, A.M. Clarifying the Epistemology of Corporate Sustainability. Ecol. Econ. 2017, 138, 40-46. [CrossRef]

91. Benn, S.; Edwards, M.; Williams, T. Organizational Change for Corporate Sustainability; Routledge: New Delhi, India, 2018.

92. Imperatives, S. Report of the World Commission on Environment and Development: Our Common Future; Oxford University Press: Oxford, UK, 1987; p. 10.

93. Available online: https:/ / www.unglobalcompact.org/library/5713 (accessed on 23 March 2021).

94. United Nations Global Compact. Leadership for the Decade of Action, in A United Nations Global Compact-Russell Reynolds Associates Study on the Characteristics of Sustainable Business Leaders; United Nations Global Compact: New York, NY, USA, 2020.

95. UN Global Compact. SDG Action Manager. 2020. Available online: https://www.unglobalcompact.org/take-action/sdg-actionmanager (accessed on 23 March 2021).

96. Danielle Duell. People with Purpose: Brisbane, QLD, Australia. 2020. Available online: https://www.peoplewithpurpose.com/ (accessed on 23 March 2021).

97. Mayer, C.P. Firm Commitment: Why the Corporation is Failing Us and How to Restore Trust in It, 1st ed.; Oxford University Press: Oxford, UK, 2013.

98. Birkinshaw, J. How is technological change affecting the nature of the corporation? J. Br. Acad. 2018, 6, 185-214. [CrossRef]

99. Ink Bank. Purpose \& Strategy: Brisbane, QLD, Australia. 2020. Available online: https://www.ing.com/About-us/Profile/ Purpose-strategy.htm (accessed on 23 March 2021).

100. Mitchell, R.K.; Agle, B.R.; Wood, D.J. Toward a theory of stakeholder identification and salience: Defining the principle of who and what really counts. Acad. Manag. Rev. 1997, 22, 853-886. [CrossRef]

101. Palombo, D. The Future of the Corporation: The Avenues for Legal Change; Hart Publishing: Oxford, UK, 2020.

102. Buckley, P.J. Can corporations contribute directly to society or only through regulated behaviour? J. Br. Acad. 2018, 6, 323-374. [CrossRef]

103. Spitzeck, H.; Chapman, S. Creating shared value as a differentiation strategy-The example of BASF in Brazil. Corp. Gov. Int. J. Bus. Soc. 2012, 12, 499-513. [CrossRef]

104. Shanahan, F.; Seele, P. Creating Shared Value. Looking at Shared Value through an Aristotelian Lens. Ethical Econ. 2017, 141-151. [CrossRef]

105. Kramer, M.R.; Pfitzer, M.W. The ecosystem of shared value. Harv. Bus. Rev. 2016, 94, 80-89.

106. Moon, H.C.; Parc, J. Shifting corporate social responsibility to corporate social opportunity through creating shared value. In Strategic Change; Wiley: Hoboken, NJ, USA, 2019. [CrossRef] 